\title{
O ENSINO JORNALÍSTICO NAS INSTITUIÇÕES UNIVERSITÁRIAS DO SUL DO BRASIL: PRESENÇA DE TEORIAS DO JORNALISMO NA GRADE CURRICULAR
}

\author{
The journalistic education in the universities in southern Brazil: presence of \\ Journalism Theories in the curriculum
}

\section{La educación periodística en las universidades del sur de Brasil: la presencia de las Teorías de Periodismo en el currículo}

Sérgio Luiz Gadini

Professor na Universidade Estadual de Ponta Grossa sergiogadini@yahoo.com.br

\section{Resumo}

O texto apresenta um retrato da oferta da disciplina de Teorias do Jornalismo nos cursos mantidos por instituições de ensino superior nos três estados do Sul do Brasil. Os dados coletados em 2014 revelam a presença de um dos eixos conceituais norteadores da formação profissional na área, considerando a perspectiva de que a legitimidade de um campo social (onde se situa a profissão de jornalista) envolve o fortalecimento de modos de entender e nomear o fazer jornalístico. Pelos dados, entre os 60 cursos mantidos por IES sediadas nos estados do Rio Grande do Sul, Santa Catarina e Paraná, 36 (ou 60\%) ofertam Teorias do Jornalismo, com mais frequência nas IES do RS. Na primeira parte, o texto traz uma contextualização história do ensino de Jornalismo no Brasil. A atualidade e a pertinência do estudo dialogam com a adaptação do projeto pedagógico e grade disciplinar, em andamento desde 2013, a partir das Diretrizes Curriculares Nacionais em Jornalismo nos cursos universitários do País.

Palavras-chave: Ensino de Jornalismo. Formação Profissional. Teorias do Jornalismo. Cursos de graduação em Jornalismo.

\begin{abstract}
This article presents a picture of subject Journalism Theories contained in course schedule that has beem held by higher education institutions (IES) in the three southern states of Brazil. Data collected in 2014 revealed the presence of one of the guiding conceptual axes of vocational training in area, considering a view that the legitimacy of a social field (where journalism is located) involves strengthening of to understand and to name the journalism production. From the data, among 60 courses held by institutions based in Rio Grande do Sul, Santa Catarina and Paraná; 60\% offer Journalism theories. This paper, in the first part, provides a historical background of journalism education in Brazil. The relevance about the study dialogue with the adaptation of course schedule, ongoing since 2013, which National Curriculum Guidelines in Journalism exists in the country.
\end{abstract}


Keywords: Journalism Eduucation. Vocation Training. Journalism Theories. Graduate courses in Journalism.

\section{Resumen}

En este trabajo se presenta un panorama de la oferta de las Teorías de Periodismo en los cursos organizados por instituciones de educación superior en los tres estados del sur de Brasil. Los datos recogidos en 2014 revelaron la presencia de uno de los ejes conceptuales rectores de la formación profesional en el área, teniendo en cuenta la evaluación de que la legitimidad de un campo social (donde se ubica la profesión de periodista) implica el fortalecimiento de las maneras de entender y nombrar el hacer periodismo. A partir de los datos, entre los 60 cursos organizados por instituciones de educación superior con sede en los estados de Río Grande do Sul, Santa Catarina y Paraná, 36 (o 60\%) proferir teorías Periodismo, con mayor frecuencia en la universidad en RS. En la primera parte, el texto trae una historia de fondo de la enseñanza del periodismo en Brasil. La pertinencia y la relevancia del estúdio dialogan con la adaptación del programa de educación y sistema disciplinario, en curso desde 2013, desde las Directrices Curriculares Nacionales de Periodismo en los cursos universitarios en el país.

Palabras clave: Periodismo Educación. Entrenamiento Vocacional. Teorías de Periodismo. Cursos de posgrado en periodismo.

\section{CONSIDERAÇÕES INICIAIS E CONTEXTUALIZAÇÃO}

Qual a situação da oferta da disciplina de Teorias do Jornalismo nos cursos de Jornalismo? Como o assunto é trabalhado nos currículos de tais cursos? Em um momento de mudança (atualização ou reforma curricular) na área, é importante dispor de indicadores que retratam a situação para, deste modo, compreender e situar o processo de adaptação às novas Diretrizes Curriculares Nacionais ao Ensino de Jornalismo, homologadas pelo Conselho Nacional de Educação (CNE) no final de 2013.

$\mathrm{Na}$ primeira parte, o texto apresenta uma contextualização história do ensino de Jornalismo no Brasil e, em seguida, os dados do levantamento empírico realizado, indicando um retrato da disciplina de Teorias do Jornalismo nas IEES do Sul do País.

Para situar este debate é preciso contextualizar e trazer alguns aspectos históricos que envolvem o surgimento da formação profissional e universitária em Jornalismo. Entre os diversos autores da área, que discutem o assunto, Elias Machado (2004) avalia que

Até a metade do século XX uma confusão epistemológica impediu a legitimação das pesquisas acadêmicas neste campo: a definição do jornalismo como uma simples prática profissional, que poderia existir sem a necessidade seja de uma formação universitária especializada, seja da produção de conhecimento sistemático. Relegado ao terreno das práticas, coube ao Jornalismo, ao menos até o final do século passado e ao contrário 
de práticas profissionais mais antigas como o Direito, um status marginal dentro das universidades. Primeiro, pela tardia incorporação à lista dos cursos oferecidos. Segundo, pelo fato de permanecer como um espaço para o ensino de técnicas, que desconsiderava a necessidade de produção de conhecimento novo como um pressuposto para a formação dos futuros jornalistas (2004)

Por esta perspectiva, Machado (2004) aponta que "o jornalismo desempenha três funções diferenciadas”: como prática profissional; objeto científico e um campo especializado de ensino.

\section{DA HISTÓRIA DO ENSINO AO ENSINO DAS TEORIAS DO JORNALISMO}

Para entender a necessidade e pertinência das Teorias do Jornalismo, é oportuno situar o surgimento e a consolidação do ensino profissional universitário na área. Alguns elementos contribuem para esta contextualização.

A história do ensino (profissional) em Jornalismo no Brasil não é consensual e se processa em movimentos simultâneos. E nem tão rápidos! A existência de uma demanda social - desde o surgimento da Associação Brasileira de Imprensa (ABI), no início do século XX - pela profissionalização do Jornalismo, impulsionada pelo crescimento dos espaços de produção noticiosa no País, será tensionada por outros atores e aspectos. Assim, de forma concreta, os primeiros cursos denominados 'livres' de formação profissional na área são realizados por iniciativa do paulista Vitorino Prata Castelo Branco (natural de Rio Claro/SP, 1904), que organiza uma série de palestras, aulas e conferências na sede da Associação dos Profissionais de Imprensa de São Paulo, chegando ao primeiro 'Curso Livre de Jornalismo' no Brasil. A informação é da pesquisa do professor Osni Dias (2004). Motivo porque se pode considerar Vitorino Branco como um dos "precursores" do ensino de Jornalismo no País.

Enquanto isso, na capital paulista, um dos empresários da mídia na época vislumbrava a urgência de profissionalizar a mão de obra para o exercício jornalístico. Considerado um "homem de jornal”, Casper Líbero, o fundador d' A Gazeta se mostrava ligado com as tendências do jornalismo. E, neste ritmo, auxiliava projetos que incluíam bibliotecas, atividades de extensão (como a 'Semana do Jornalista', em janeiro/1940), o apoio a eventos (como o I $^{\circ}$ Congresso dos Jornalistas Profissionais em 1942) e uma proposta de curso universitário para formação em jornalismo, que adquire forma alguns anos depois, em 1947.

Um ano depois (1948) a Universidade do Brasil (que, mais tarde se torna, Federal do Rio de Janeiro, funcionando na Escola de Comunicação/ECO, em 1967) instala, junto à 
PROGRAMA DE PÓS-GRADUAÇÃO EM COMUNICAÇÃO DA UNIVERSIDADE FEDERAL DE SANTA MARIA

Faculdade de Filosofia, o primeiro curso de Jornalismo na então capital federal. O curso de Jornalismo foi criado pelo Decreto-Lei ${ }^{\circ}$ 5.840, de 13 de maio de 1947, que instituiu o curso de jornalismo como parte do sistema de ensino superior, mas inicia atividades no ano seguinte. A primeira turma de graduados em Jornalismo pela Faculdade de Filosofia cola grau em 1950.

Poucos anos depois, surge a primeira escola de Jornalismo no Sul do Brasil. Criado pelo Decreto-lei 29.831, de 1951, do Governo Federal, o Curso de Jornalismo se torna a base da Faculdade de Comunicação Social (Famecos) da Pontifícia Universidade Católica do Rio Grande do Sul (PUC-RS), mantida pela congregação religiosa marista (inicialmente na Faculdade de Filosofia da PUC, junto ao Colégio do Rosário, e mais tarde, em uma escola tradicional da Av. Ipiranga, em Porto Alegre). Autorizado, o curso de Jornalismo passa a funcionar no ano letivo de 1952, com uma primeira turma de 64 ingressantes no mês de março. Em 11/04/1956, o Decreto federal $N^{o} 39.008$, reconhece o Curso de Jornalismo da PUC-RS.

Em 1961, após um intenso trabalho profissional de Luiz Beltrão, a Universidade Católica de Pernambuco cria o primeiro curso de Jornalismo no Norte/Nordeste do País. Oportuno lembrar que, já em meados dos anos 1950, Beltrão exerceu um papel similar ao que Vitorino Prata realizou em São Paulo: ministrando cursos livres de formação em diversas cidades do interior do País, especialmente no Nordeste.

A tradicional Escola de Comunicações Culturais (depois, ECA) da Universidade de São Paulo só passa a contar com um curso de Jornalismo em 1967, rodando seu primeiro jornal laboratório no final de 1968, em um dos momentos mais trágicos da repressão política no Brasil. E, a partir do início dos anos 1970, no auge da repressão militar, é o momento da capital mineira contar com um curso de Jornalismo. A PUC Minas cria a Faculdade de Comunicação, em 1971, onde passa a funcionar o Curso de Jornalismo. E, em 1978, é a vez da PUC de São Paulo também criar seu Curso de Jornalismo.

$\mathrm{Na}$ maioria dos casos, a criação dos cursos surgiu por demandas crescentes por profissionalização da produção jornalística, tensionada por ações e iniciativas de trabalhadores em sintonia com alguns empresários ou mesmo por setores de administração universitária de instituições de ensino.

E, em tais contextos, nem sempre a clareza da necessidade de contar com disciplinas ou programas conceituais (teorias) em Jornalismo eram visíveis ou estavam em sintonia com tais projetos de gestão acadêmica. E, pois, uma reflexão similar se poderia fazer sobre o espaço e ação dos ingressantes estudantes de Jornalismo junto ao movimento estudantil, que 
operava entre a clandestinidade e a busca de expressão política ou cultural. Era o clima da repressão ditatorial vigente!

Uma análise cuidadosa da grande curricular dos primeiros cursos de Jornalismo do País, ainda disponíveis, indica que o projeto da Católica de Pernambuco, muito provavelmente por iniciativa de seu fundador (Luiz Beltrão), era um dos que mais abria espaço para disciplinas conceituais voltadas ao Jornalismo (como ética e teorias, paralelamente ao ensino técnico na área).

Os efeitos da política de polarização do pós-guerra no Brasil, entretanto, se fazem sentir mais fortemente alguns anos depois. Isso porque, em 1945, não se pode afirmar que a universidade brasileira era uma instituição nacionalmente consolidada como projeto de País. Daí o 'efeito' da política da ONU, via Unesco, em um País que, ainda, buscava um rumo ou identidade própria.

Eduardo Meditsch (1992) lembra o papel do CIESPAL (Centro Internacional de Estudios Superiores en Comunicación para América Latina), criado em 1959, e passando a operar em 1960, com o objetivo de 'tecnicizar' o ensino universitário, em uma perspectiva de enfraquecimento das áreas de ciências sociais e humanas. Era o clima da guerra fria, em que a política dos EUA ditava as apostas estratégicas na América Latina para "despolitizar" o risco de leitura crítica na universidade. E o ensino de Jornalismo, em especial, as escolas que foram surgindo, coincidentemente neste período, como momento de expansão dos serviços urbanos no Brasil, embarcou nessa.

No entanto, com poucas escolas de Jornalismo, pela dimensão geográfica do Brasil, não se pode afirmar que isso teve impacto muito expressivo na resistência política ao regime militar. Isso porque, por ocasião do golpe (março/1964), o País contava com apenas quatro cursos de Jornalismo em atividade organizada.

Pode-se dizer, sem dúvida, que a formação dos docentes que buscavam referência bibliográfica, ou mesmo cursos em países latinos, tenha registrado influência, uma vez que o CIESPAL se tornou, em poucos anos, um referência irradiadora junto aos emergentes cursos de Jornalismo, com oferta de indicações, convites e intercâmbio, sob claro controle da política de alinhamento da ONU/Unesco. Esta perspectiva se mantém hegemônica até o final dos anos 1970, quando os debate em torno do relatório McBride (Um mundo e muitas vozes) coloca em risco a versão dominante nos estudos de comunicação na América Latina.

$\mathrm{Na}$ avaliação de Marques de Melo (2006), registra-se, ao longo deste período de mais de duas décadas, uma espécie de 'crise' conceitual no campo da formação profissional e acadêmica em Jornalismo. 
PROGRAMA DE PÓS-GRADUAÇÃO EM COMUNICAÇÃO DA UNIVERSIDADE FEDERAL DE SANTA MARIA

O campo do Jornalismo enfrenta múltiplas turbulências nesta passagem de século. Mudanças tecnológicas, trabalhistas e geopolíticas atropelam os processos de produção noticiosa, impondo ajustes aos novos tempos. Profissionais, empresários e educadores procuram soluções consensuais para corresponder às novas demandas do mercado e da sociedade (MELO, 2006; p.9).

A onda de urbanização, crise econômica e tentativa e superação do período ditatorial não resolveram alguns dos dilemas de segmentos importantes da profissionalização, como é o caso de setores de serviço, como o Jornalismo.

E, pois, o País chega ao final dos anos 1980 com um registro de 100 cursos de graduação em Comunicação Social, entre as várias habilitações profissionalizantes, onde Jornalismo se mostra a mais procurada. Exceto São Paulo e Rio de Janeiro, que contavam com cerca de 20 e 15 instituições com cursos na área, Minas Gerais, Rio Grande do Sul, Bahia e Paraná registravam cerca de 5 cursos por estado. As demais unidades da federação contavam com um, dois ou no máximo três cursos de Comunicação Social. Assim, com algumas exceções, até a virada dos anos 1980/90, o número de faculdades de Jornalismo no Brasil parece estar associado ao crescimento urbano populacional do País no mesmo período.

No início dos anos 1990, o ensino em Jornalismo registra uma busca crescente por vagas na Universidade. Pela projeção da época, considerando que a economia crescia e a Universidade pública - em parte pressionada pela redução de verbas e arrocho salarial docente - não ofertava vagas suficientes, o ensino privado avançou rápido com abertura de novos cursos na área. A tal expansão do ensino particular parecia uma promessa em sintonia com a onda neo-liberalizante da economia brasileira, marcada pela privatização de serviços essenciais e entrega de segmentos estratégicos para grupos empresariais transnacionais. A propaganda, contudo, se mostrava mais pesada que a realidade social. E não durou mais de uma década o 'boom' da abertura indiscriminada de centenas de faculdades de Comunicação, com ênfase no Jornalismo.

Ainda que a Internet só abriria para acesso comercial no final de 1994, a expectativa com as transformações tecnológicas também contagiava a promessa de facilitação na oferta do ensino privado no campo da mídia. Ficaria mais simples fazer TV, cinema, rádio ou jornal. Ao Estado, pois, caberia assegurar a 'ampliação' generalizada da oferta de vagas, mesmo que, em muitos casos, instituições reivindicavam a abertura de cursos sem qualquer condição de estruturas laboratoriais e tampouco política de pessoal para manter quadros docentes. Por consequência, se as IEES eram privadas poderiam cobrar mensalidades, justificadas pela lógica de um serviço comercial em oferta. Fosse educação, saúde ou qualquer setor essencial 
PROGRAMA DE PÓS-GRADUAÇÃO EM COMUNICAÇÃO DA UNIVERSIDADE FEDERAL DE SANTA MARIA

seria detalhe, pois a relação mercantil (oferta $\mathrm{x}$ procura) deveria resolver, quase que naturalmente.

E não precisou mais de uma década para confirmar que as mesmas IES que reivindicavam abertura de oferta de vaga no ensino superior, na base da crítica ao modelo de universidade pública engessada (e sem condições de atender demanda crescente), operavam apenas no limite da mercantilização da educação. E, assim, a ampliação ou promessa de democratização do acesso universitário não passou de retórica, pois a porta de entrada era a mesma que excluía pela limitação do poder aquisitivo da maioria da população.

De toda forma, foi a década de 1990 que registrou o maior crescimento da oferta de cursos universitários em Jornalismo, passando de cerca de IES para mais de 250 cursos em cerca de 10 anos.

A ampliação da oferta de vagas na área também pode ser relacionada ao surgimento de novos cursos de pós-graduação (stricto sensu), que a partir do início dos anos 1990 também deixa de ser exclusividade do eixo Rio/São Paulo/Brasília, registrados até então, com novos programas (PPGCom) que passam a funcionar na região metropolitana de Porto Alegre/RS, Salvador e depois Belo Horizonte. Mesmo que tais cursos de pós-graduação não centravam em Jornalismo, é inegável que tais ofertas ampliam possibilidades de estudos e investigações também em Jornalismo, na medida em que docentes e profissionais passam a buscar tais programas com mais possibilidade de cursar pós-graduação.

E, por consequência, a crescente constatação em torno da necessidade de criar disciplinas ou tópicos de programas em atividades com ênfase em Teorias do Jornalismo se tornam, cada vez mais, uma realidade, ainda que tal ritmo de crescimento não seja tão rápido, se comparado por exemplo ao caso português, que em poucos anos, após o fim da ditadura (1974), registra condições para estudos específicos em Jornalismo, a partir da Universidade Nova de Lisboa e outras instituições que, por sua vez, ajudam a impulsionar leituras e pesquisas em universidades brasileiras a partir de meados dos anos 1990. Esta situação, aliás, registra uma rápida adesão, chegando no início da década seguinte (2001) com a constatação de que um dos autores mais citados nos estudos em Teorias do Jornalismo no Brasil seja o português Nelson Traquina.

Em função deste e outros aspectos, o crescimento da pós-graduação em Comunicação Social no Brasil é apontado por José Marques de Melo como uma outra variável a ser considerada neste cenários em que se pensa e situa a presença ou emergência das Teorias do Jornalismo. Melo observa que, até início de 2000, 
poucas escolas possuíam disciplinas de fundamentação conceitual e, em consequência, inibiam ou desestimulavam a reflexão sobre os fenômenos jornalísticos. O giro em torno do universo comunicacional (genérico, abrangente e não raro abstrato) embotava o desejo de repensar criticamente os processos de criação, produção, difusão e recuperação das notícias e seus subprodutos (interpretativos, opinativos, utilitários, etc) (MELO, 2006; p. $13)$.

A lenta inserção de disciplinas ou, em alguns casos, de tópicos sobre Teorias do Jornalismo em disciplinas afins - em geral, isso ocorria em Teorias da Comunicação ou mesmo Estudos Culturais ou mesmo Semiótica, quando tais disciplinas possuíam uma carga horária - foi, aos poucos, e diferentes situações, possibilitando o reconhecimento de que a necessidade de Teorias específicas em torno do eixo conceitual do curso ofertava passa a ganhar adesão de docentes e pesquisadores das mais diversas disciplinas afins.

A reprodução de textos de livros de autores que publicavam em língua portuguesa sobre Teorias do Jornalismo - em alguns casos, traduções de obras norte-americanas - ganha, a partir de meados dos anos 1990 um impulso de diálogos conceituais, que passam a ver em tais autores um reconhecimento que, até aquele momento, parecia ignorado ou mesmo negado em inúmeros cursos de Jornalismo de diferentes IES brasileiras. Não por acaso, na virada dos anos 1990, Nelson Traquina - com traduções, ensaios ou textos em coletânea - se torna, em menos de três anos, um dos autores mais lidos nas escolas de Jornalismo, quando o assunto é conceitos, teorias e inclusive métodos de investigação jornalística.

A rápida expansão comercial da internet, a partir de 1995 no Brasil, se torna logo outro fator que impulsiona o acesso e divulgação de autores que passam a influenciar a latente necessidade de se falar, pensar e reconhecer a urgência de Teorias do Jornalismo... nos Cursos de Jornalismo no Brasil!

\section{MÉTODO UTILIZADO E RECORTE (EMPÍRICO) DO ESTUDO}

O texto apresenta um retrato da oferta da disciplina de Teorias do Jornalismo nos cursos de Jornalismo mantidos por instituições de ensino superior nos três estados do Sul do Brasil $^{1}$. Os dados coletados no início de 2014 revelam a presença (ou ausência) de um dos eixos conceituais norteadores da formação profissional na área, considerando a perspectiva de que a legitimidade de um campo social (onde se situa a profissão de jornalista) envolve o

\footnotetext{
${ }^{1}$ Os dados apresentados neste texto integram o estudo realizado, junto ao Programa de Mestrado em Jornalismo da UEPG, que contou com a participação da estudante de Jornalismo Tais Borges de Macedo, como bolsista de Iniciação Científica (PIBIC/CNPq-UEPG, entre 2013-2014), sob o título "o espaço da crítica de cultura e de mídia nos cursos de Jornalismo do Sul do Brasil".
} 
fortalecimento de modos de entender e nomear o fazer jornalístico. $\mathrm{O}$ estudo constata que, entre os 60 cursos mantidos por IES sediadas nos estados do Rio Grande do Sul, Santa Catarina e Paraná, 36 (equivalente a 60\%) ofertam a disciplina de Teorias do Jornalismo, com maior concentração nas instituições localizados no RS.

O levantamento, realizado em um momento de transição e reforma curricular, considerando diretrizes nacionais ao ensino de Jornalismo homologadas pelo Ministério da Educação em 2013, revela que o reconhecimento da importância das teorias do Jornalismo na formação profissional já indica um realidade que tende a se fortalecer, tendo em vista que a maioria das IES projeta novas versões de grade curricular a partir de 2015, em sintonia com a nova regulamentação do MEC.

Tabela 1 - Cursos de Jornalismo no Sul do País:

\begin{tabular}{|l|l|l|}
\hline Estado & $\mathbf{N}^{\mathbf{0}}$ de Cursos & IES com Teorias do Jornalismo (\%) \\
\hline PR & 22 & 11 IES $=50 \%$ \\
\hline SC & 16 & 9 IES $=55 \%$ \\
\hline RS & 22 & 16 IES $=75 \%$ \\
\hline
\end{tabular}

Fonte: Gadini, 2015.

O estudo foi realizado a partir de um levantamento exploratório, identificando a presença da disciplina de Teorias do Jornalismo, tendo por base as IES que ofertam curso na área, em um momento de transição e adaptação curricular, considerando a exigência regulamentar do Ministério da Educação ao ensino superior na área. A investigação realizou buscas nos sites de todas as IES que ofertam curso de Jornalismo no Sul do Brasil e, quando tais informações não estavam disponíveis, a alternativa foi enviar mensagem eletrônica ou mesmo obter tais dados por contato telefônico, visando garantir um retrato mais próximo possível da realidade.

A expectativa, de levantar tais indicadores antes da implantação das reformas curriculares, também vem ao encontro de uma perspectiva analítica - que norteia o presente estudo - que considera como um dos pressupostos da legitimidade social de um campo profissional a oferta de espaços ao ensino das principais teorias que orientam a existência e fortalecimento do referido campo (jornalístico). Em seguida, o estudo apresenta ainda os principais tópicos dos programas mais frequentes trabalhados em Teorias de Jornalismo.

O compus empírico do presente estudo compreende o universo total das instituições de ensino superior (universidade, faculdade ou centro universitário), seja de ordem pública, privada ou sem fins lucrativos, que ofertam cursos de Jornalismo nos três estados do Sul do Brasil. Assim, foram consultadas ou pesquisadas 22 IES no Paraná, 16 em Santa Catarina e 22 
no Rio Grande do Sul, que atualmente mantêm oferta de vaga no ensino regular presencial em Jornalismo. A escolha da amostra, tendo por base empírica a região Sul, considera os dados do Instituto Nacional de Pesquisas Educacionais (INEP), órgão do Ministério da Educação responsável pela autorização, reconhecimento e validade do ensino superior, que registra em 2014350 cursos de Jornalismo em funcionamento no Brasil.

Assim, a amostra regional, que contempla cerca de $18 \%$ do total de IES com oferta de vaga na área, é representativa, ainda que limitada ao alcance dos três estados que compreendem o universo analisado. Oportuno informar que das 60 IES que integram a amostra do estudo apenas $20 \%$ são universidades públicas, entre estaduais ou federais. As demais são particulares ou comunitárias sem fins lucrativos.

Tabela 2 - Disciplina de Teorias do Jornalismo nos Cursos de IES no Sul do Brasil:

\begin{tabular}{|c|c|}
\hline Instituição & Carga Horária \\
\hline FACCREI (PR) & $40 \mathrm{~h}$ \\
\hline FAG (PR) & $72 \mathrm{~h}$ \\
\hline FASUL (PR) & $72 \mathrm{~h}$ \\
\hline PUCPR & $40 \mathrm{~h}$ \\
\hline SECAL (PR) & $36 \mathrm{~h}$ \\
\hline UEPG (PR) & $68 \mathrm{~h}$ \\
\hline UNINTER (PR) & $80 \mathrm{~h}$ \\
\hline UTP (PR) & $36 \mathrm{~h}$ \\
\hline UEL (PR) & $72 \mathrm{~h}$ \\
\hline UNIBRASIL -PR & $40 \mathrm{~h}^{2}$ \\
\hline FADEP (PR) & $80 \mathrm{~h}^{3}$ \\
\hline FURB (SC) & $36 \mathrm{~h}$ \\
\hline IELUSC SC) & $60 \mathrm{~h}$ \\
\hline UFSC SC) & $72 \mathrm{~h}$ \\
\hline UNESA/FESSC & $36 \mathrm{~h}$ \\
\hline UNIARP SC) & $60 \mathrm{~h}$ \\
\hline UNOCHAPECÓ & $60 \mathrm{~h}$ \\
\hline FACVEST SC) & $30 \mathrm{~h}$ \\
\hline UNIVALI SC) & $30 \mathrm{~h}$ \\
\hline UNIDAVI SC) & $72 \mathrm{~h}^{4}$ \\
\hline UCPEL (RS) & $30 \mathrm{~h}$ \\
\hline
\end{tabular}

${ }^{2} \mathrm{O}$ curso da Unibrasil (de Curitiba/PR) oferta a disciplina Teorias da Notícia (com 40 horas).

${ }^{3}$ A coordenação do curso da FADEP (de Pato Branco/PR) informa que o conteúdo de Teorias do Jornalismo é contemplado pela disciplina Teorias e Técnicas Jornalísticas, ministrada no primeiro semestre, com 80 horas.

${ }^{4}$ O Curso da UNIDAVI (de Rio do Sul/SC) oferta a disciplina Fundamento da Notícia, com 72 horas, no primeiro semestre, onde estaria presente o conteúdo de Teorias do Jornalismo. 
PROGRAMA DE PÓS-GRADUAÇÃO EM COMUNICAÇÃO DA UNIVERSIDADE FEDERAL DE SANTA MARIA

\begin{tabular}{|l|l|} 
UFPEL (RS) & $60 \mathrm{~h}$ \\
\hline UFRGS (RS) & $120 \mathrm{~h}$ \\
\hline UFSM (RS) & $45 \mathrm{~h}$ \\
\hline ULBRA (RS) & $68 \mathrm{~h}$ \\
\hline UNICRUZ (RS) & $60 \mathrm{~h}$ \\
\hline UNIFIN (RS) & $64 \mathrm{~h}$ \\
\hline UNIFRA (RS) & $51 \mathrm{~h}$ \\
\hline UNIJUI (RS) & $60 \mathrm{~h}$ \\
\hline UNISC (RS) & $60 \mathrm{~h}$ \\
\hline UNISINOS (RS) & $60 \mathrm{~h}$ \\
\hline UNIVATES (RS) & $60 \mathrm{~h}$ \\
\hline URCAMP (RS) & $54 \mathrm{~h}$ \\
\hline UNIPAMPA -RS & $60 \mathrm{~h}^{5}$ \\
\hline ESPM (RS) & $72 \mathrm{~h}$ \\
\hline FAL (RS) & $72 \mathrm{~h}$ \\
\hline
\end{tabular}

Fonte: Gadini, 2015.

\section{ENTRE DESAFIOS E EXPECTATIVAS}

Mesmo com cursos universitários criados em 1947 (Casper Líbero) e 1948 (Universidade Federal do Rio de Janeiro), o Brasil só vai registrar um reconhecimento público - via produções editoriais, com lançamentos, bem como pesquisas e o reconhecimento de cursos de pós-graduação na área e, por consequência, interesse concreto em Teorias do Jornalismo - a partir do início do século XXI. "Somente na virada do século (XX/XXI) é que a Teoria do Jornalismo começou a ser reconhecida e adotada por parte significativa dos cursos de Jornalismo do Brasil”, diz Eduardo Meditsch (Traquina, 2004; p. 12). E isso que a ‘explosão' de cursos universitários é registrada a partir do início dos anos 1990, quando o País passa de pouco mais de 100 para cerca de 300 cursos em apenas uma década.

O Jornalismo é um meio de conhecimento social, pela divulgação da informação atenta da atualidade, através da descrição da singularidade dos acontecimentos que a constituem e a sua exposição ao público em tempo hábil para sua utilização. E informação é poder, pois não se pode exercer a cidadania de maneira eficaz sem informação confiável para embasar nossa intervenção social, política e econômica (MEDITSCH, 2012; p.21).

E como se pode fazer isso, a partir das escolas de Jornalismo? É este o objetivo que as Diretrizes Nacionais Curriculares ao Ensino de Jornalismo buscam apontar, indicando os elementos - e jamais uma receita - para orientar a formação profissional e acadêmica na área.

\footnotetext{
${ }^{5} \mathrm{Na}$ URCAMP (de Bagé/RS) o curso registra a disciplina Teoria e Técnica em Jornalismo e PP (com 54 horas de duração), que busca contemplar o conteúdo de Teorias do Jornalismo.
} 
Nada muito ousado, além do que já se verifica, de Norte a Sul do País, em inúmeros universidades. No entanto, era preciso, com certa urgência, indicar um rumo, envolvendo perspectivas conceituais e metodológicas ao ensino, extensão, pesquisa e formação profissional no campo jornalístico.

Os próximos anos, contudo, podem registrar um reconhecimento mais rápido, ao menos se depender da regulamentação por parte do Ministério da Educação, com diretrizes curriculares ao ensino de Jornalismo, homologadas em 2013, depois de vários anos em debate, a partir de entidades representativas da área.

Pelo texto das Diretrizes Nacionais Curriculares, entre as competências cognitivas do jornalista formado destaca-se o desafio de "compreender as especificidades éticas, técnicas e estéticas do jornalismo, em suas complexidades de linguagem e como forma diferenciada de produção e socialização de informação e conhecimento sobre a realidade" (MEC, 2013).

É nesta perspectiva, que coloca o ensino de Teorias do Jornalismo nos cursos específicos da área como um "estranho" silenciamento, buscando compreender o cenário e, ao mesmo tempo, trazendo alguns indicadores das condições de oferta do ensino em 2014, em um momento de transição, que aponta para uma reconfiguração do campo de formação profissional na área. E, por fim, o texto apresenta ainda os principais pontos do conteúdo programático mais frequente nos cursos que já ofertam a disciplina de Teorias do Jornalismo, considerando a amostra da presente pesquisa.

A análise em torno da existência da disciplina de Teorias do Jornalismo nos cursos da área, na região Sul do Brasil, ainda que se trata de um momento de transição, na reconfiguração da grade curricular, indica uma presença em fase de consolidação e reconhecimento da importância de estudos conceituais na formação acadêmica e profissionalizante em Jornalismo. Não se trata de um consenso, mas de um retrato da realidade do ensino universitário que aponta para um fortalecimento e ampliação da presença da disciplina de Teorias do Jornalismo, considerando que se trata de um dos eixos norteadores que pautam as diretrizes curriculares nacionais vigentes na área.

E, aqui, é oportuno destacar que o texto das DCN em Jornalismo (2013), entre as competências cognitivas, no processo de formação da área, a compreensão das “especificidades éticas, técnicas e estéticas do jornalismo, em sua complexidade de linguagem e como forma diferenciada de produção e socialização de informação e conhecimento sobre a realidade". E, na sequencia, orienta para "discernir os objetivos e as lógicas de funcionamento das instituições privadas, estatais, públicas, partidárias, religiosas ou de outra natureza em que o jornalismo é exercido, assim como as influências do contexto sobre esse exercício". 
A elaboração do Projeto Pedagógico do curso de bacharelado em jornalismo deverá observar os seguintes indicativos: (...) c) orientar a formação teórica e técnica para as especificidades do jornalismo, com grande atenção à prática profissional, dentro de padrões internacionalmente reconhecidos, comprometidos com a liberdade de expressão, o direito à informação, a dignidade do exercício profissional e o interesse público (DCN, 2013; art. $\left.4^{\circ}\right)$.

Ao considerar essas mesmas orientações ao projeto pedagógico e curricular, os cursos da área dispõem de elementos norteadores que devem, gradualmente, fortalecer as perspectivas de formação conceitual na área de Jornalismo, seja pelas disciplinas de teorias ou de metodologia na pesquisa específicas com objeto investigativo voltado ao conhecimento específico que caracteriza a produção periodística.

A tendência, portanto, indica uma revalorização conceitual ao campo jornalístico, o que também pode impulsionar o desenvolvimento de outras possíveis investigações na área, sem desconsiderar a oportuna e sempre necessária contribuição de abordagens interdisciplinares, como uma das marcas da produção científica nas mais diversas áreas do conhecimento nas sociedades contemporâneas.

Um outro foco da presente investigação, que deve resultar em texto a ser apresentado em outros momentos, diz respeito ao conteúdo programático mais habitualmente encontrado nas disciplinas de Teorias do Jornalismo oferta, entre 0 final de 2013 e o primeiro semestre de 2014, nas instituições de ensino superior que mantêm oferta de Curso de Jornalismo na Região Sul do Brasil. O assunto, interesse e estudo na área, portanto, registra outros inúmeros desdobramentos e desafios, típico de uma realidade em transição, mas que aponta para uma consolidação e fortalecimento da formação acadêmica e conceitual em dos campos que integram a área de Comunicação Social no Brasil.

\section{REFERÊNCIAS}

BELTRÃO, Luiz. Teoria e prática do Jornalismo. Adamantina/SP: Edições Mnia, 2006.

DIAS, Osni Tadeu. "Vitorino Prata Castelo Branco e o primeiro Curso Livre de Jornalismo do Brasil". Trabalho apresentado no GT História do Jornalismo no II Encontro Nacional da Rede Alfredo de Carvalho. Florianópolis, UFSC, 15 a 17 de abril de 2004.

GADINI. Sérgio Luiz. "Alguns desafios para a formação profissional em Jornalismo". Anuário Unesco/Metodista de Comunicação Regional, Ano 13 n.13, p. 29-38, jan/dez. 2009. Disponível em: https://www.metodista.br/revistas/revistasims/index.php/AUM/article/viewFile/2186/2112 
HIME, Gisely V. C. "Na Fundação da Primeira Escola de Jornalismo do Brasil Cásper Líbero Gera o Conceito de Jornalismo Moderno". In: Revista PJ:Br - Jornalismo Brasileiro. Ed. 3, $1^{\circ}$ semestre/2004. www2.eca.usp.br/pjbr/arquivos/artigos3_b.htm

KIMURA, Mônica. "Resgate de um veículo pioneiro"(Entrevista Ethevaldo Siqueira). In: $\mathrm{PJ}: \mathrm{Br}$ - Jornalismo Brasileiro, $1^{\circ}$ semestre/2003.

www2.eca.usp.br/pjbr/arquivos/entrevistas_001.htm

MACHADO, Elias. "Dos estudos sobre o Jornalismo às Teorias do Jornalismo: Três pressupostos para a consolidação do jornalismo como campo de conhecimento". In: Revista eletrônica e-compós, $\mathrm{N}^{\mathrm{o}}$ 1, Dez/2004. Disponível em http://www.compos.org.br/e-compos

MEDITSCH, Eduardo. Pedagogia e pesquisa para o Jornalismo que está por vir. Florianópolis: Insular, 2012.

MELO, José M. Teoria do jornalismo: identidades brasileiras. São Paulo: Paulus, 2006.

MICK, Jacques (coord). Quem é o jornalista brasileiro? Florianópolis: UFSC, 2012. Disponível em http://perfildojornalista.ufsc.br/files/2013/04/Perfil-do-jornalista-brasileiroSintese.pdf Acesso em 15/02/2015.

Resolução CNE/CES 1/2013. Diário Oficial da União, Brasília, $1^{\circ}$ de outubro de 2013 Seção 1 - p. 26. Diretrizes Curriculares Nacionais para o curso de Jornalismo, bacharelado, e dá outras providências. Disponível em http://portal.mec.gov.br/dmdocuments/documento_final_cursos_jornalismo.pdf Acesso em $10 / 02 / 2015$.

ROCHA, P.M., CAMARGO, I.O. e GADINI, S.L. "O ensino de jornalismo cultural a partir da crítica". Texto apresentado no I Confibercom ( $I^{\circ}$ Congresso Mundial de Comunicação Ibero-americana). São Paulo: Socicom/USP, 1 a 4 de agosto de 2011. Disponível em www.confibercom.org/anais2011/pdf/333.pdf

SCHIMIDT, Cristina. "Folkcomunicação: estado do conhecimento sobre a disciplina". In: Bibliocom - Revista editada pela Sociedade Brasileira de Estudos Interdisciplinares da Comunicação - Intercom. Ano 1, $1^{\text {a }}$ edição, 2008. Disponível em:

http://www.portcom.intercom.org.br/revistas/Ano1|\#01|novembro e dezembro de 2008

SCHUCH, Hélio Ademar. “Adequação do ensino na formação de jornalistas”. In: Revista Brasileira de Ciências da Comunicação. Vol. XXV, nº1, janeiro/junho de 2002.

TRAQUINA, Nelson. Teorias do Jornalismo (Vol. I). Florianópolis: Insular, 2004.

ZUCULOTO, Valci. "Riscos (e avanços) do Jornalismo na profissão e na academia". In: CHRISTOFOLETTI, R. e LIMA, S. (orgs). Reportagem, pesquisa e investigação. Florianópolis: Insular, 2012. Pp: 93-111. 
Sérgio Luiz Gadini

Possui graduação em Comunicação Social - Jornalismo pela Universidade Federal de Santa Maria (1990). Mestrado em Jornalismo pela Universidade Estadual de Ponta Grossa (UEPG). Doutorado em Ciências da Comunicação pela Universidade do Vale do Rio dos Sinos (2004), tendo cursado o Programa Doutorado sanduíche (pela Capes) junto à Universidade Nova de

Lisboa, em Portugal. Atualmente é professor associado (concursado) da Universidade Estadual de Ponta Grossa, Paraná.

Esta obra está licenciada sob uma Licença Creative Commons. 